\title{
DE LA EDIFICACION EN ALTURA EN CHILE
}

Oscar Ortega S.

Patricio Hermosilla $G$.

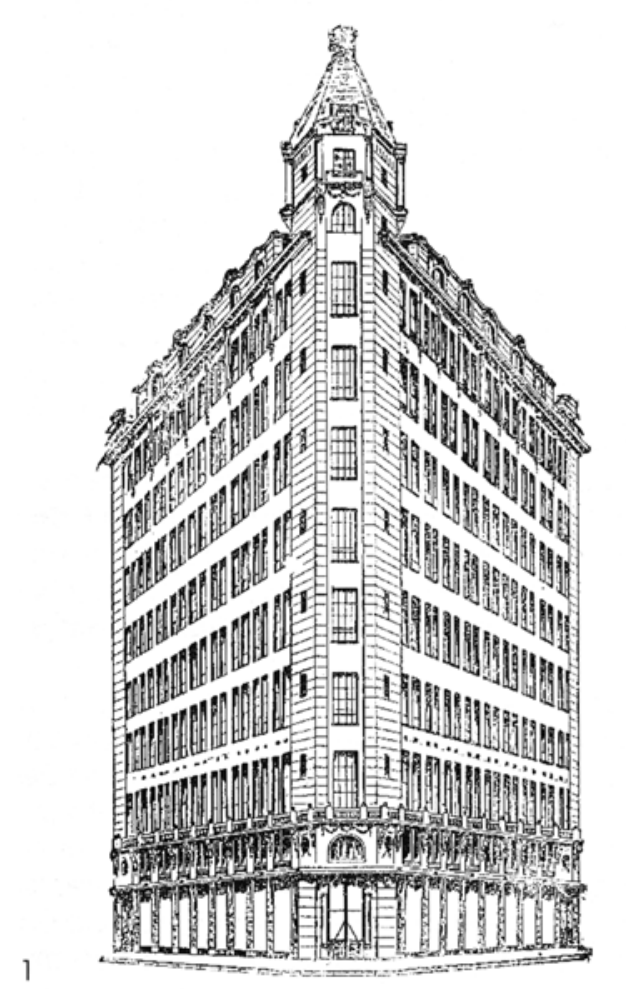

Circunstancias económicas, tecnológicas y políticas, unidas a la voluntad de transformaciones urbanas, hacen posible la irrupción de la edificación en altura en los años 20 en Santiago y Valparaíso. El centro de estas ciudades modifica sus espacios públicos y renueva la imagen construida en los sectores representativos de la autoridad gubernamental y del poder financiero.

Economical, technological and political circumstances, as well as the will to generate urban transformations, enabled the introduction of highrises in Santiago and Valparaiso in the 20's. The downtown areas in these cities underwent important changes in their public spaces, altering the urban image in the financial and civic centers. a edificación en altura, como expresión de una utopía de las sociedades moder- nas, se origina en EE. UU. de Norteamérica. específicamente en las ciudades de Chicago y Nueva York, que compiten desde fines del S.XIX por superar marcas con edificios altos que denominaron "rascacielos".

Diversas circunstancias posibilitaron la aparición de estos edificios. Las principales fueron, en lo técnico, el desarrollo de sistemas de comunicación en altura (ascensores de personas (1) y teléfonos), así como instalaciones de energía (electricidad y gas) y sanitarias; también de nuevos sistemas estructurales y constructivos, como las estructuras formadas por marcos de acero. En lo económico, la existencia de recursos financieros para acometer obras mayores y la escasez de suelo en áreas de alto valor. En lo expresivo, el tipo "rascacielos" es consecuencia de lenguajes formales ("estética de la altura") y de significados sociales.

En 1984 se celebró el centenario de la construcción del "Home Insurance Building" en Chicago, primer rascacielos en la historia de la arquitectura. Originalmente de diez pisos (luego se le agregaron otros dos), fue proyectado por el Arquitecto W. Le Baron Jenney. En N.York, en 1888 fue levantado el "Tower Building", de 11 pisos, proyecto de B. Lee Gilbert, que se ha considerado el primer rascacielos de Manhattan. En 1927 "el número de rascacielos en la isla de Manhattan es 2.000" (2).

En América Latina la edificación en altura se inició muy posteriormente y alcanzó un número de niveles y magnitudes inferiores a las de sus modelos norteamericanos. Con excepción de algunos casos en Río de Janeiro, San Pablo y Buenos Aires (3), en otras ciudades este tipo arquitectónico recién se aplicó a partir de la tercera década del siglo XX. No sólo fue una consecuencia del desarrollo económico. En los países andinos la condición de área frecuentemente expuesta a sismos contribuyó a inhibir su construcción. Algunos de los primeros casos fueron: en Bogotá el edificio "Cubillos" de ocho pisos, obra del Arqto. A. Manríquez M., construido en 1927; en Lima el edificio "Gildemeister" de cinco pisos, proyecto del Arquitecto alemán W. Benno L., levantado en
1929: en Quito el edificio "Banco La Previsora" de ocho pisos, proyectado en EE. UU. y construido en 1935; en Caracas el edificio del Ministerio de Educación, de cuatro pisos según proyecto del Ingeniero $G$. Salas y construido en 1938. Cabe hacer notar el paralelismo con el desarrollo de este tipo en Europa. En 1931 el edificio más alto de Londres y que mereció una distinción de la R.I.B.A. fue el del "London Transport Executive" de la calle Broadway 55, de los Arqtos. Adams, Holden y Pearson, que contaba con sólo ocho pisos.

Para América Latina, M. Cuadra (4) plantea la tesis de reconocer tres fases en la historia de la edificación en altura: fase de introducción al medio local, fase de consolidación y fase de desarrollo propio.

El presente trabajo se refiere a la primera fase en nuestro país y es parte de la investigación "La edificación en altura en Chile". (5).

Cuando hablemos de edificación en altura, deberá entenderse que se trata de obras que poseen más de cinco niveles útiles sobre el terreno, que requieren de equipos especiales y servicios e instalaciones adecuados para funcionar correctamente, $y$ en los cuales hubo de emplearse una tecnología propia de un grado superior de desarrollo.

\section{PERIODO DE INTRODUCCION (1920 - 1940).}

Hacia 1900, Chile vivía el agotamiento de un sistema político y social que se mostraba inadecuado para enfrentar los desafios que presentaba el nuevo siglo. Más tarde, los efectos de la postguerra se hicieron sentir, no sólo en sus consecuencias económicas sino también en las costumbres y aspiraciones del ciudadano común. Simultáneamente el país pasó de la dependencia económica británica, característica del siglo XIX, a la dependencia económica norteamericana.

Esta situación contribuyó a la inestabilidad de una economía basada fundamentalmente en la minería (salitre, carbón, cobre) y en la agricultura. Se exportaba materia prima y se importaba manufactura.

En Santiago, que contaba en 1910 con 350.000 habitantes, parte de esto se expresaba en los anhelos oficiales y privados de contar con planes de desarrollo urbano y en ma-
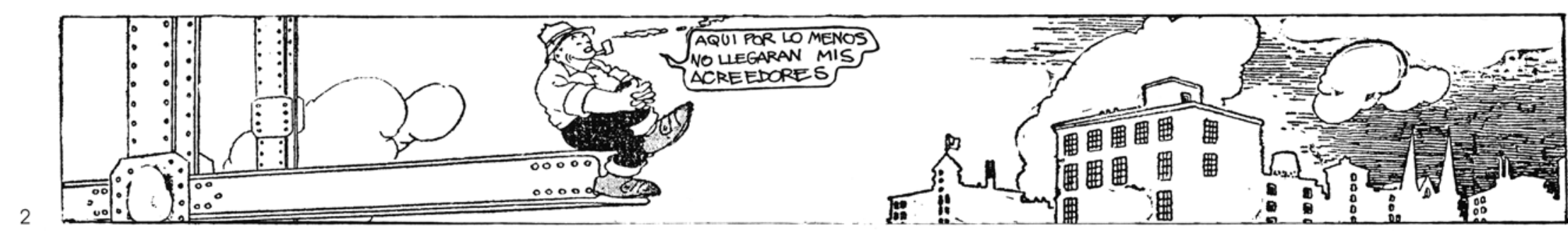

FIGURAS 

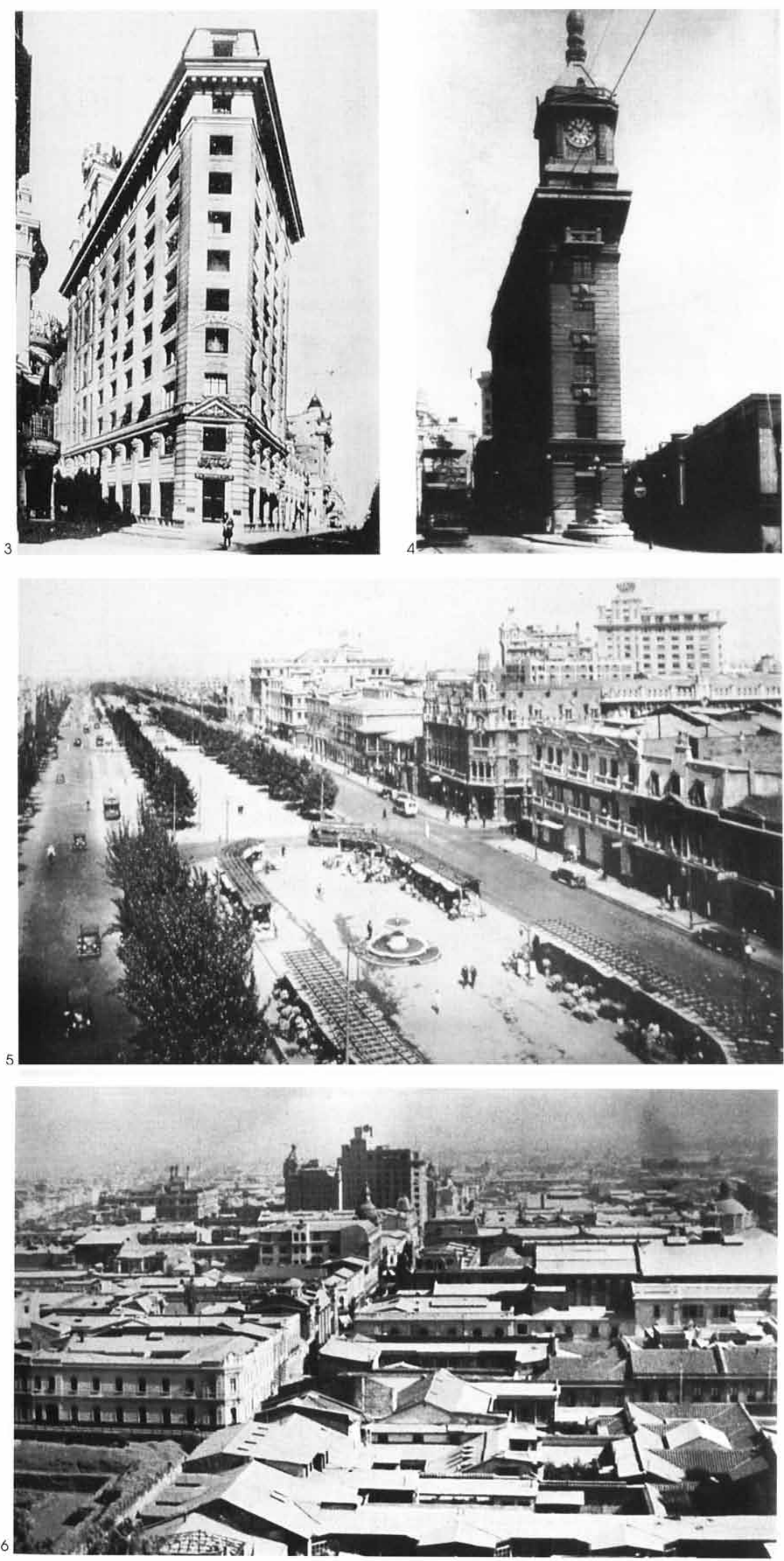

3. Edificio E. Diaz. Foto Merton, en: A. y A.D. N N 11, Santiago, 1930 Edificio Reloj Turri. Prat y Cochrane, Valparaiso. A.A.B.. U.F.. U. de
Alameda de las Delicias. Santiago 1930. Edificios Ariztia y Díaz A.A.B.U.F. U. de Chile. terializar cambios visibles que dejaran atrás conceptos formales considerados decaden tes. Se vislumbraba una revolución técnica con la introducción de un material: el hormigón armado (6), de la mecanización y de una nueva infraestructura. Circularon tranvías eléctricos (1900), se instaló alumbrado eléctrico (1904), fue construido el sistema de alcantarillado público (1907), se creó en La Calera la primera fábrica de cemento, se canalizó el río Mapocho, se aplicó asfalto a las calles que antes tenían piedras de rio (1906) y, posteriormente, operaron autobuses (1923)

En 1909 se creó el "Comité de Transformaciones de Santiago" aprobándose luego la Ley 2.203 sobre construcciones y urbanizaciones en la ciudad. En todos los ámbitos se aspiraba lograr la modernización.

En 1920 se realizó el ler. Congreso Panamericano de Arquitectos, en Uruguay donde la delegación chilena presentó la ponencia "Transformación, ensanche y embelle cimiento de la ciudad tipo predominante en América" en la que se recomendaba: "pro ceder a la transformación y ensanche de las principales ciudades americanas de acuerdo a principios modernos de urbanización

Bajo estas circunstancias y ambiente propicio a las expresiones nuevas, es que se de sarrolló el período que llamaremos de introducción de la edificación en altura en Chile, y teniendo como escenarios exclusivos a Santiago y Valparaíso

Numerosas son las razones que explican la voluntad de usar este tipo arquitectónico. Algunas objetivas, como la creciente falta de terrenos centrales y la política de aumento de la densidad de edificación expresada por el gobierno municipal. Otra, subjetiva y tal vez la que mayor impulso otorgó a la implantación de ella, fue la busqueda de símbolos que expresaran el poder e iniciativa de la autoridad en momentos de transformaciones sociales y económicas.

Y es este anhelo de lograr una imagen urbana similar a la que representa a las metrópolis más desarrolladas, lo que lleva a repeti ingenuamente modelos foráneos insertándolos en la trama tradicional.

En la remodelación de sectores centrales de Santiago se emplearon incluso los nombres "Nueva York", "París", "Londres" para nuevas calles. El trazado de éstas, ya sea por la incorporación de ejes diagonales o líneas curvas permitió singulares perspectivas y nuevos ángulos de visión para los futuros edificios.

Esta caracteristica fue aprovechada en el emplazamiento de los volúmenes, consiguiendo con este artificio, destacar la altura como magnitud predominante.

\section{Los primeros edificios.}

En una de estas remodelaciones urbanas (calles Nueva York y La Bolsa, 1913) fue donde se levantó el primer rascacielos chileno: el edificio construido en 1921 por encargo del Senador Rafael Ariztía, según proyecto del Arquitecto Cruz (7). Esta obra fue motivo de asombro y orgullo para los santiaguinos. Su cuerpo prismático de 52 metros de altura sobrepasaba largamente todas la construcciones de la ciudad, incluyendo la cúspide de las torres de las iglesias (8).

El edificio "Ariztía" consta de catorce pisos de altura: dos en sótano, diez destinados a oficinas y dos en una torre rematando en un faro luminoso. El total, concebido dentro de un esquema clásico, se compone de una base de dos pisos, un cuerpo y un remate superior Su estructura simétrica, está formada por muros, pilares, vigas y losas de hormigón armado 
en un sistema rígido. Las luces mayores alcanzan 4.5 metros entre apoyos.

Posteriormente, en el año 1925 y vecino al anterior, se construye el edificio "Díaz", segundo ejemplar de este tipo. Proyectado por Valdivieso (9) y de La Cruz (10), posee una altura total de $55 \mathrm{~m}$., cuenta con once niveles y un cuerpo de remate que albergó un sistema luminoso de publicidad. En sus proximidades, en calle Bandera, se levantan otros edificios dedicados a servicios financieros y oficinas: en la esquina suroriente de Agustinas el Arqto. Cruz Montt proyectó en 1927 un edificio de 6 pisos que incluye una galería comercial desde la cual se accede a las oficinas de los pisos superiores. De Siegel y Siegel (11) es el proyecto para el edificio de la Compañía La Sudamérica, de diez pisos $\left(7.973 \mathrm{~m}^{2}\right.$. de superficie) y planta libre en base a pilares y vigas. terminado de construir en 1931 en la esquina surponiente de Agustinas

Hacia fines de la década del 20 se remodelaron dos de los bordes que delimitaban la Plaza de Armas de Santiago. Se buscaba entregar una imagen de modernidad y desarrollo al más importante y tradicional centro ciudadano. Para conseguirlo fueron demolidas valiosas obras de no más de 50 años y se proyectaron cuerpos de mayor altura que el resto de los edificios históricos que completaban el conjunto. Fueron producto de esta remodelación el edificio "Portal Bulnes" en el borde oriente de la plaza, proyectado por el Arqto. Arteaga (12), terminado de construir en 1931; el edificio de calle Monjitas № 860 , de nueve pisos, obra de Slegel y Geiger (13), de 1928, que configura una nueva calidad de espacio público desde el que se accede a un estacionamiento subterráneo de automóviles. En el borde sur el nuevo "Portal Fernández Concha" intervenido por los arquitectos Smith (14) y Arteaga en 1928. A este edificio que poseía tres niveles de estilo neoclásico francés. se le agregaron otros tres niveles y una fachada racionalista con detalles barrocos

En el mismo sector, calle Compañía 1034. otro ejemplo es el edificio Teatro Real con 10 pisos de oficinas y 1 sala de espectáculos, según proyecto de Valdivieso y De la Cruz de 1930.

En la plaza Baquedano, límite de la ciudad tradicional y puerta de acceso a la llamada "ciudad jardín" que nacía en el sector oriente, en 1929 el Arqto. G. Schneider (15) proyectó el conjunto "Edificios Turri", formado por un volumen central de ocho pisos de altura y dos laterales de cinco pisos. Su construcción fue terminada en el año 1931. A pesar de ocupar toda la longitud de una cuadra, su tratamiento en base a cuerpos diferenciados conforma un conjunto articulado con un ritmo de claro dominio vertical. Su primer nivel estaba destinado a comercio y los superiores a vivienda. El edificio central albergaba además una sala de cine, otro de los símbolos de la modernidad de la época.

En el mismo sector, y con frentes de $9 \mathrm{~m}$. a Alameda y al Parque Forestal. L. Kulczewski (16) proyectó y construyó en 1928 un edificio de seis niveles destinados a viviendas con "pozos de luz" para iluminar los recintos.

En Valparaíso, A.Cruz y T. Armstrong proyectan el edificio para el Banco Edwards, de 9 pisos en calle Arturo Prat esquina Urriola, el que se construye en 1924. A esta fecha ya están construidos el edificio denominado Reloj Turri, por encargo de A.Edwards y el edificio del Banco Anglo Sud Americano del Arquitecto inglés Collins.

A su vez R.Larrain (17), desde su cargo como arquitecto de la Caja de Crédito Hipo-
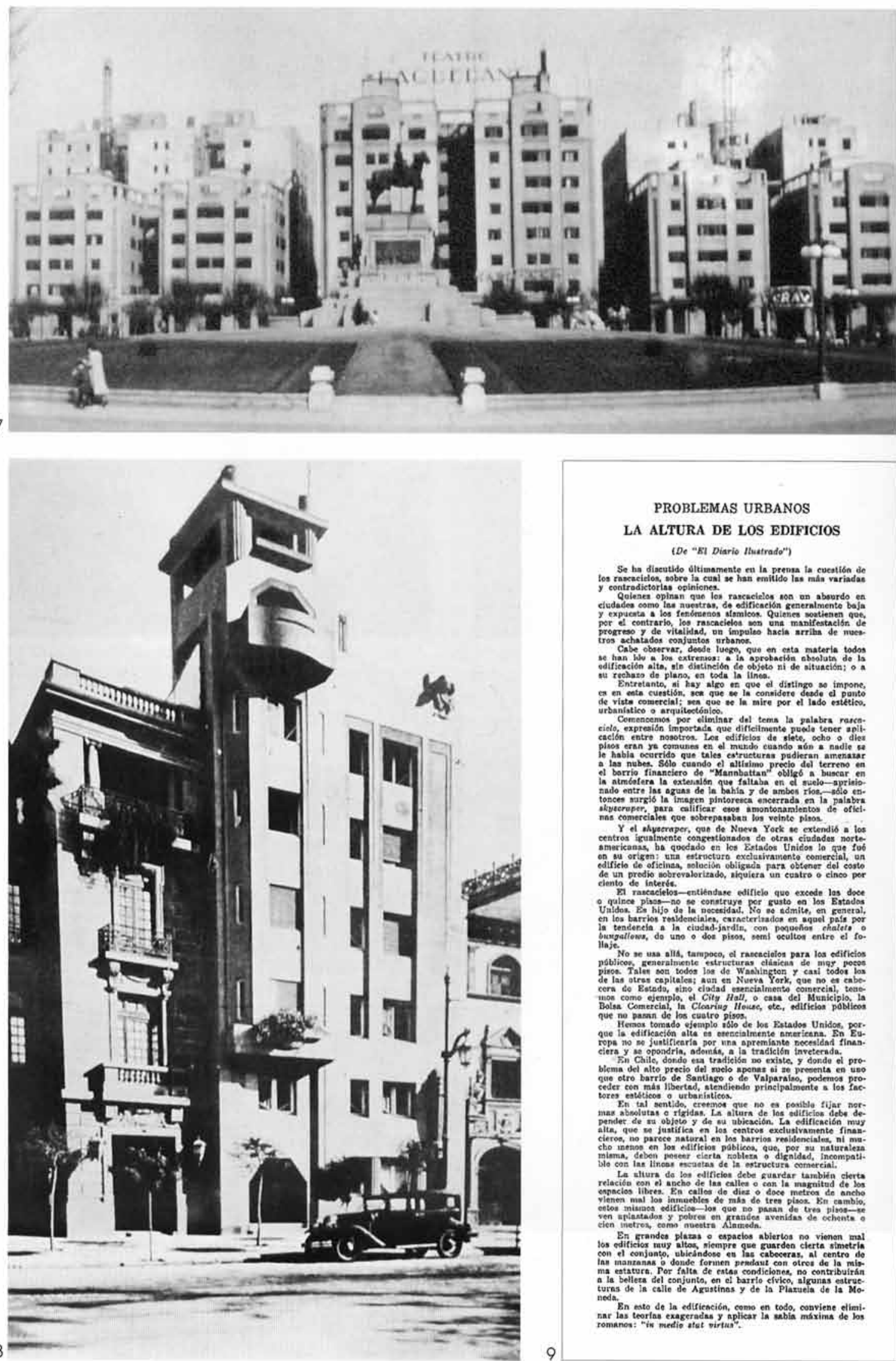

PROBLEMAS URBANOS LA ALTURA DE LOS EDIFICIOS (De "Bl Diario Huatrade"t)
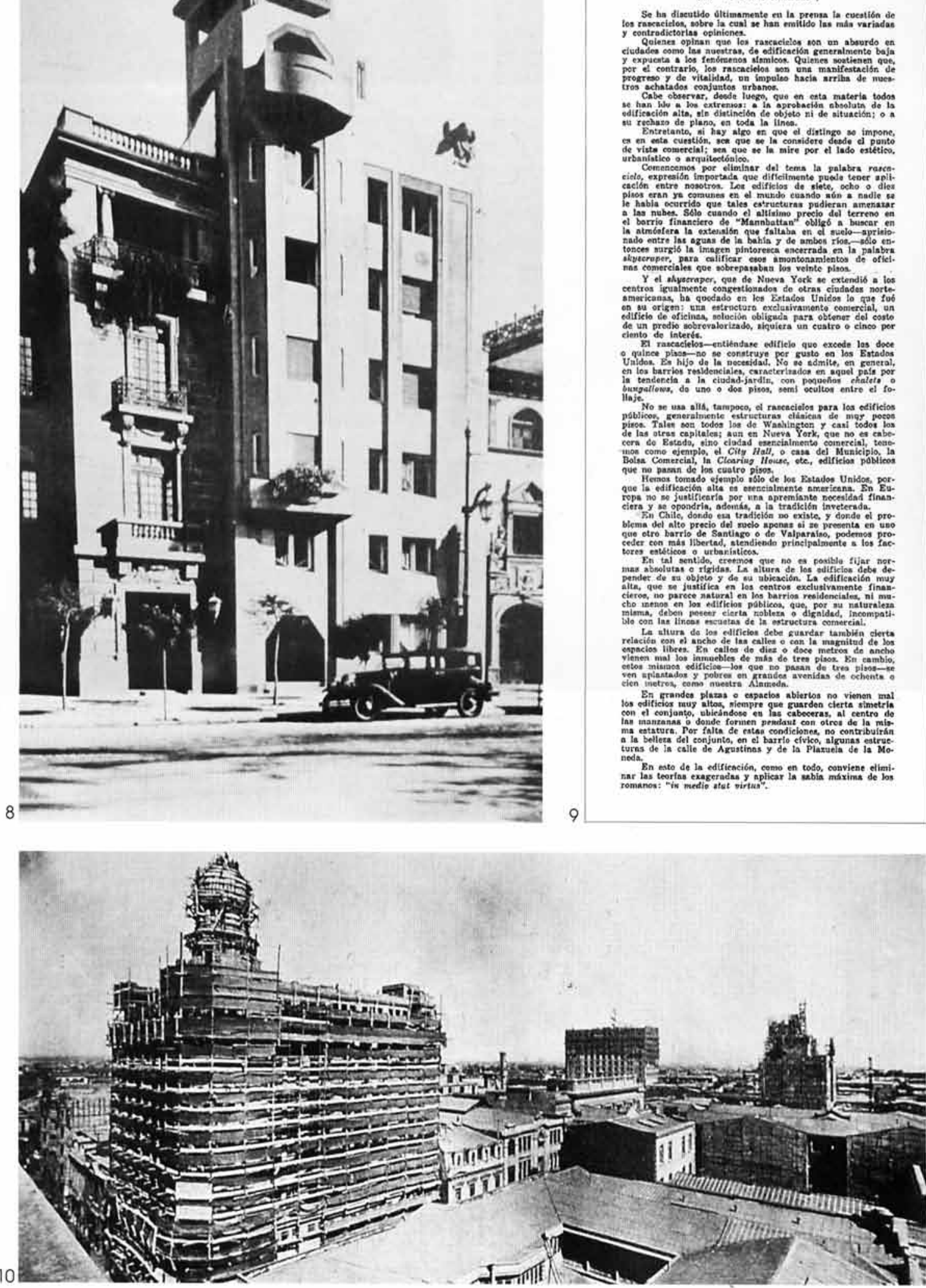

Edificios Turr, 1929 aprox. Plaza Baquedano, Santiago. Tarjeto postal. Foto Mora Edificio en Parque Forestal, de L. Kulc
Y A.D. N 6 Y 7.1929 .
Articulo en: El Diario llustrado, y reproducido por Revista A. y A.D. jullio 1930

Construcción de los edificios La Sud América. La Nación y Ministerio de Hacienda. Foto A. Y A.D N² 11.1930. 


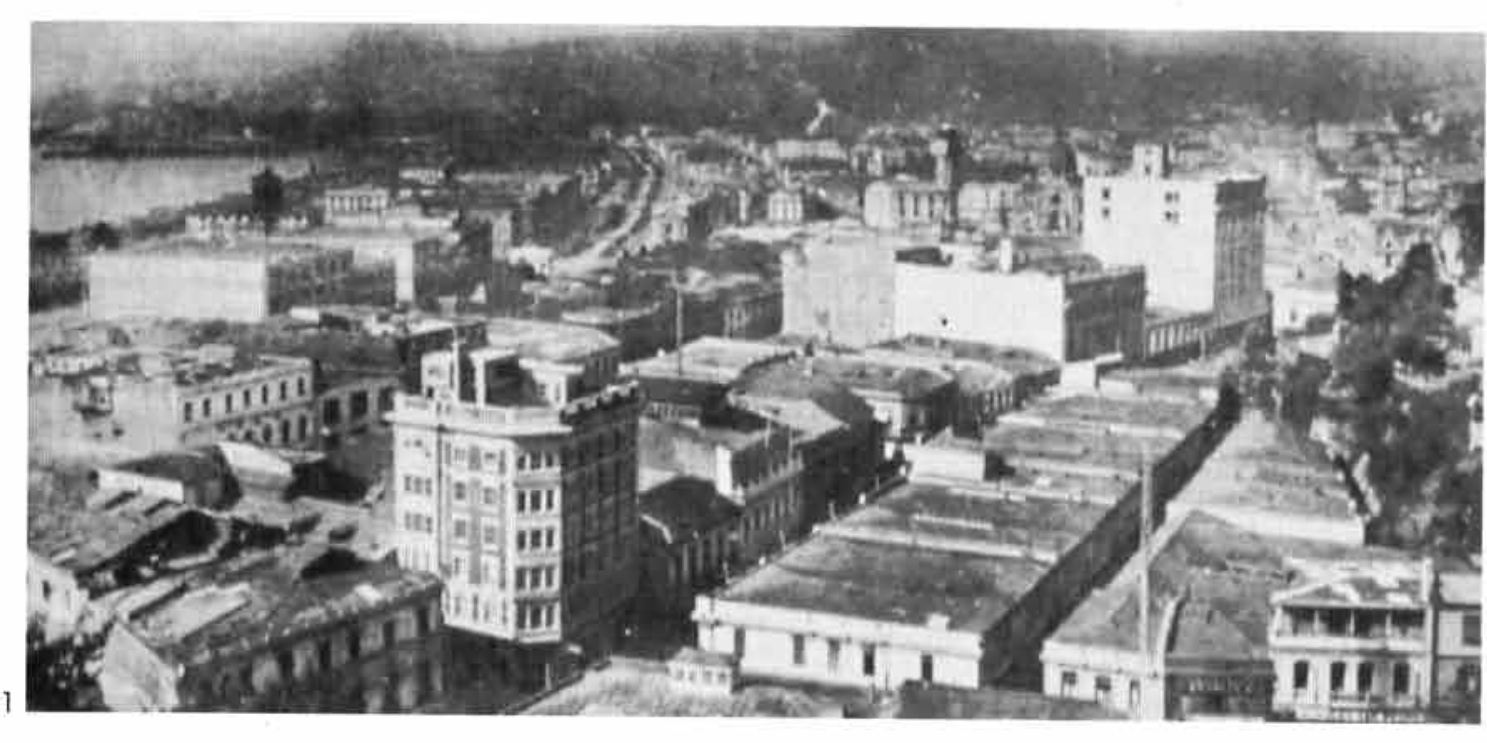

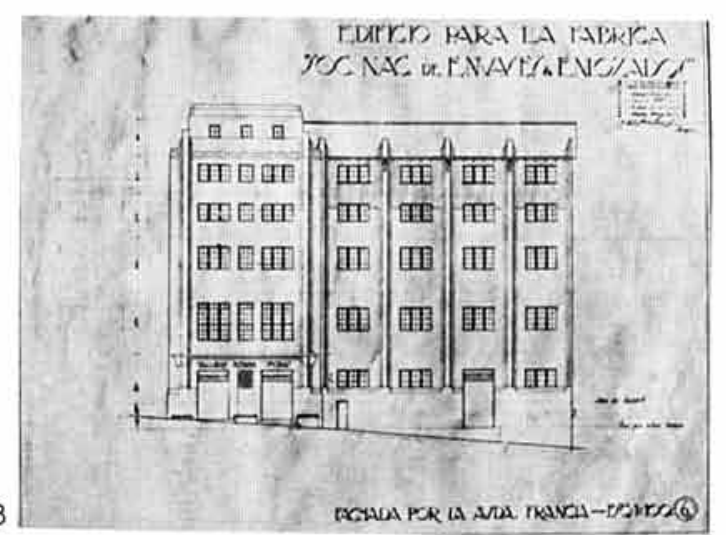
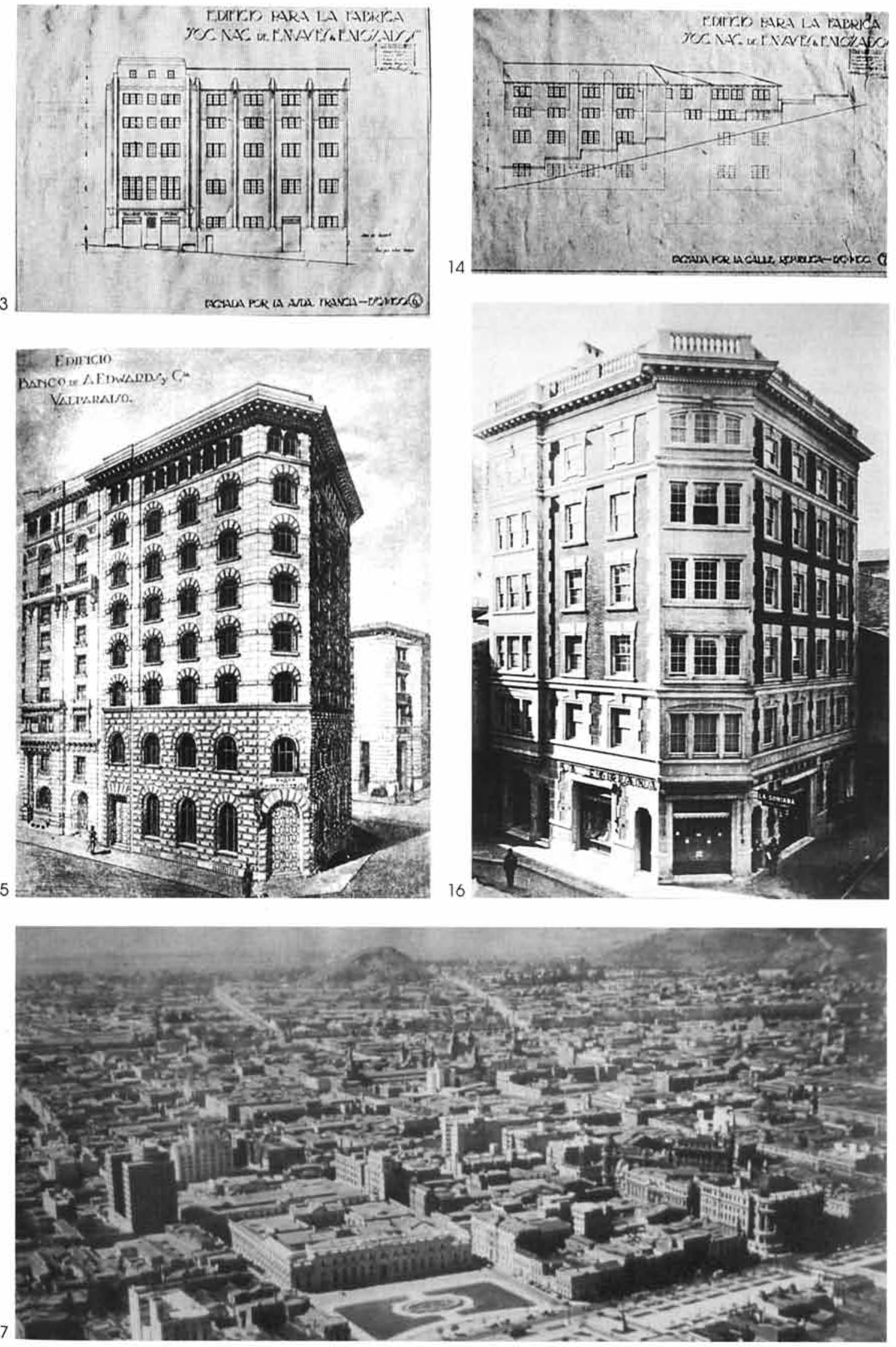

11. Centro de Valparaíso, y Edif. Fundación Santa Maria. Revista A, y A.D. marzo 1929

Arato Collins, Londres. En: Catálogo OTis

3 y 14 . Edificio para la fábrica Sociedad Nacional de Envases y

Enlozados Valparaiso.
Edificio Banco Edwards, actuales Juzgados. Vecino, edificio de

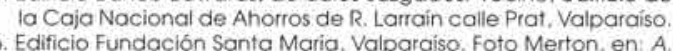
Y A.D., marzo 1929 .
Centro de Santiago, remodelación Barrio Civico. 1933 gprox.

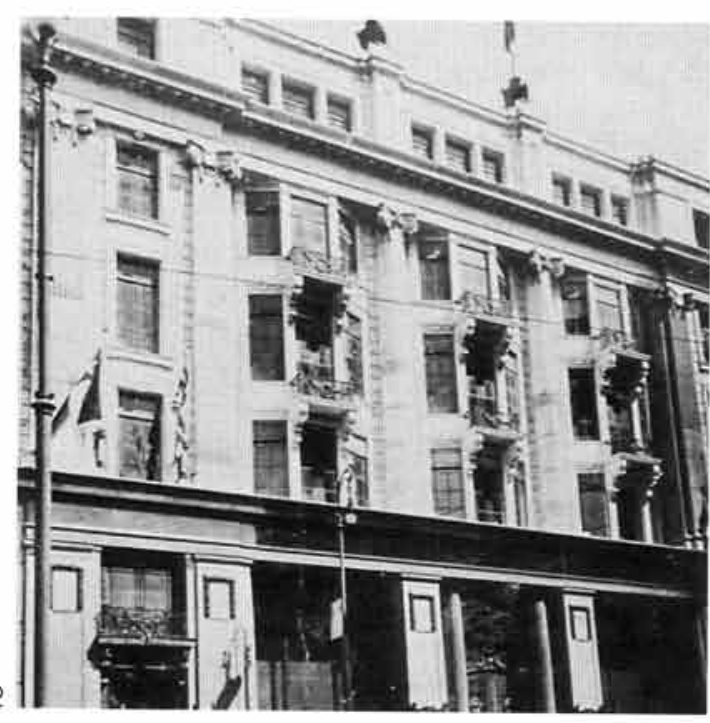

tecario proyectó y construyó en la calle Prat e Edificio Comercial de la Caja Nacional de Ahorros, de once pisos de altura.

"Valparaíso se está poblando de rasca cielos, en el plan, hacia donde convergen todos los negocios. En la calle Prat ya erigen a cielo, airosos sus líneas de decenas de metros" (La Nación, Santiago, Domingo 12 de octubre. 1924).

En la misma ciudad en 1928, T. Armstrong (18) construyó para la Fundación Santa María un edificio de rentas de 6 pisos, ubicado en la esquina de calles Condell y Bellavista. Es de interés también mencionar el edificio proyectado en 1928 para la fábrica Sociedad Nacional de Envases y Enlosados por el Arqto. Sasso (19) en Avda. Francia y calle República: que resuelve las diferencias de nivel del terreno mediante un cuerpo de tres y seis pisos según la calle que enfrente.

\section{El Barrio Cívico}

Simultáneamente, el alto índice de desempleo producto de la recesión mundial, unida a la crisis del salitre, hicieron que el gobierno chileno dispusiera de ambiciosos planes de obras públicas para absorver mano de obra desocupada.

Así surgió el caso de remodelación urbana más significativo en Santiago por el tamaño del área comprendida: el entorno del Palacio de La Moneda donde se proyectó y construyó el "Barrio Cívico".

Esta transformación comprendió la construcción de la fachada sur de La Moneda en 1927, según proyecto de J. Smith S. la demolición de una manzana construida para destinarla a área libre (Plaza 5 de Septiembre, hoy Plaza de la Constitución), una plaza central en la Alameda y la reconstrucción de sus bordes con edificios en altura, de modo de proporcionarlos a los nuevos espacios vacios y realzar, por contraste, el edificio neoclásico de Palacio de Gobierno. En diez años se consolidó gran parte del sector con edificios de trece o más pisos destinados a servicios gubernamentales, oficinas y viviendas. También se habilitaron tres plazas: de la Constitución, de la Libertad y Bulnes, comprendiendo espacios al Sur de la Alameda. Para ellos se había elaborado diversos proyectos (los "oficiales": de Smith Solar y Smith Miller; de Karl Brunner; de C. Vera M. (20)). Las primeras obras levantadas fueron: en 1929, el edificio para el diario "La Nación" (doce pisos), proyectado por el Arqto. R. Barceló, (21), calle Agustinas № 1269: en 1930, el de la Dirección de Correos y Telégrafos (seis pisos) y, posteriormente, el del Servicio de Seguro Social (trece pisos), según proyectos de R. González (22) y A. Fuentealba (23). 

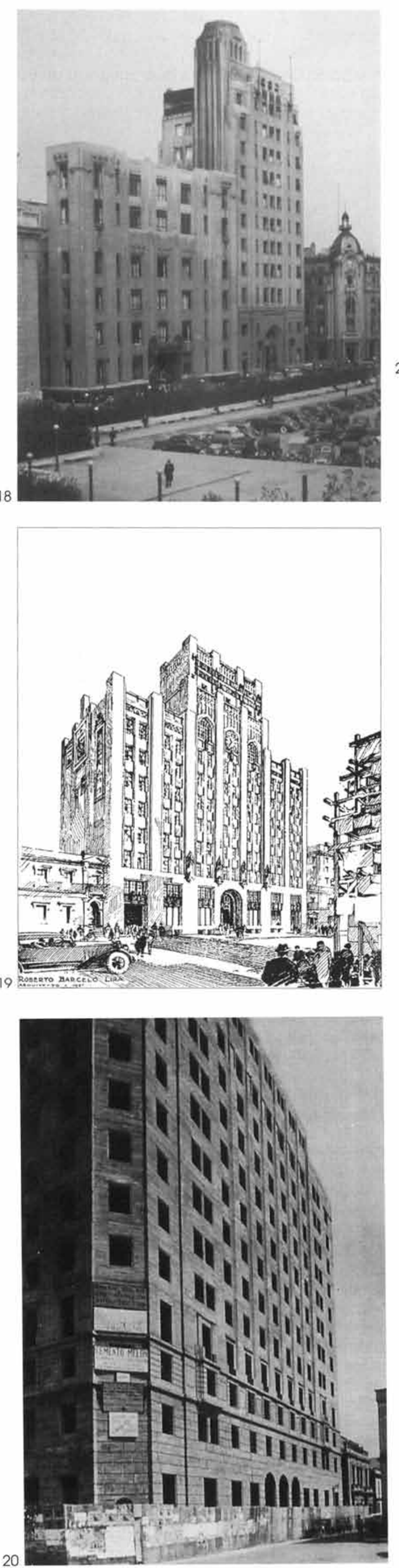

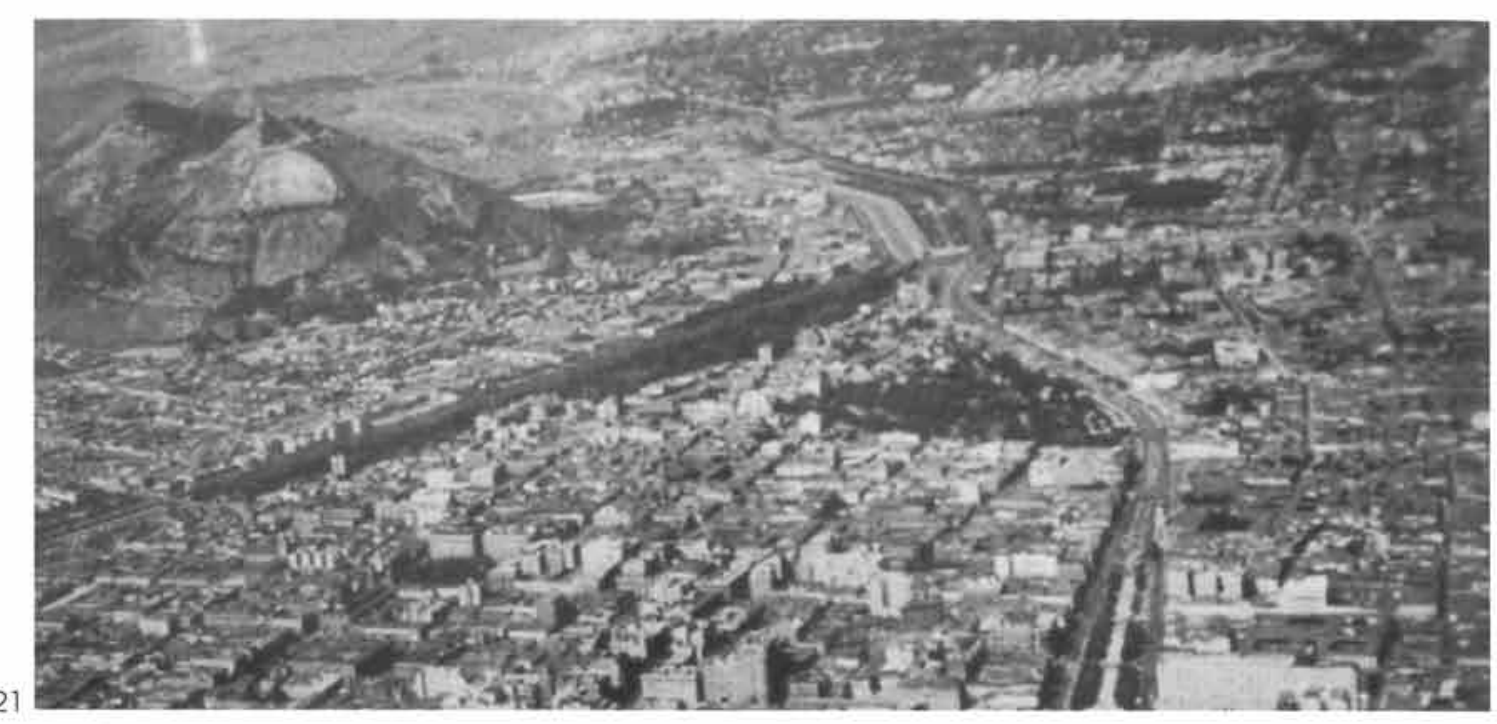

En 1933 el Ministerio de Hacienda y en 1936 el Hotel Carrera, ambos de trece pisos y proyectados en 1929 y 1934, respectivamente, por la oficina de Smith Solar y Smith Miller (24). En el mismo sector, en 1931, según proyecto de los Arqtos. F. de la Cruz y H. Rojas, (25) se construye el gran edificio de renta de la Caja de Retiro y Montepio de la Defensa Nacional, obra que configura con diez pisos, todo el borde oriente de la calle Teatinos entre Agustinas y Huérfanos. También en la esquina N.O. de Agustinas y Morandé los Arqtos. José Carlés y Guillermo Kaulen construyeron en 1936 un edificio de nueve pisos, financiado con fondos previsionales del Banco de Chile.

Otro hito a señalar es el conjunto de edificios de la manzana comprendida entre las calles Huérfanos y Agustinas, Estado y Ahumada de seis y siete niveles, proyectados entre 1928 y 1935 por los Arqtos. Siegel y Siegel, destinados a locales comerciales, oficinas y un cine. La agrupación mantiene el bloque de manzana urbana compacta y con similar altura y expresión de fachadas.

En su esquina nororiente (Huérfanos y Estado), en 1929, se inicia la construcción del edificio Oberpaur según proyecto de los arquitectos Arteaga y Larraín (26) y cálculo estructural del Ing. Bruno Ebsner. Terminado en 1932, ha sido reconocido como el primer edificio en altura que incorpora el lenguaje moderno y en que el justo empleo del hormigón armado se expresa en sus formas y espacialidad.

De mediados de esta década deben mencionarse algunos ejemplos de gran significación que son obra de algunos precursores nacionales en la adhesión al pensamiento arquitectónico moderno. Entre ellos el edificio de nueve pisos, "Caja de Amortización", de H. Mardones (27), que servirá de pauta para la altura de los edificios posteriormente construidos en la calle Bandera. Otro ejemplo es la obra resultado de un concurso (1934), de los arquitectos Costabal. (28) Garafulic (29) y Del Río(30), el "Edificio Ferrocarriles del Estado", hoy Ministerio de Vivienda y Urbanismo en la Alameda B. O'Higgins № 924 que, concebido como edificio-manzana, resuelve su masa de siete y nueve niveles mediante la articulación del volumen, acusando accesos y redondeando las esquinas. También, en la proximidad del cerro Santa Lucía, en la esquina de las calles Santa Lucía y Merced, se construye en 1934, el edificio residencial de diez pisos proyectado por Arteaga y Larrain

En Valparaíso, constituyéndose en hito del puerto y articulando los espacios de la plaza Sotomayor, la estación del ferrocarril y el muelle Prat, en 1936 se construyen dos torres de ocho pisos, proyectadas por los Deptos. de Ar18. Plaza de la Constifución, edificios Dirección de Correos y
Telégratos y Caja del Seguro Obligatorio, 1936 aprox. A.A.B.,U.F.
U. de Chile.

9. Edificio del Diario La Naciòn. Dibujo publicado en: A. y A.D. febrero 1929.

20. Construcción del Ministerio de Haclenda antes de la demolición del Ministerio de Guerra. A.A.B. U.F. U. de Chile.
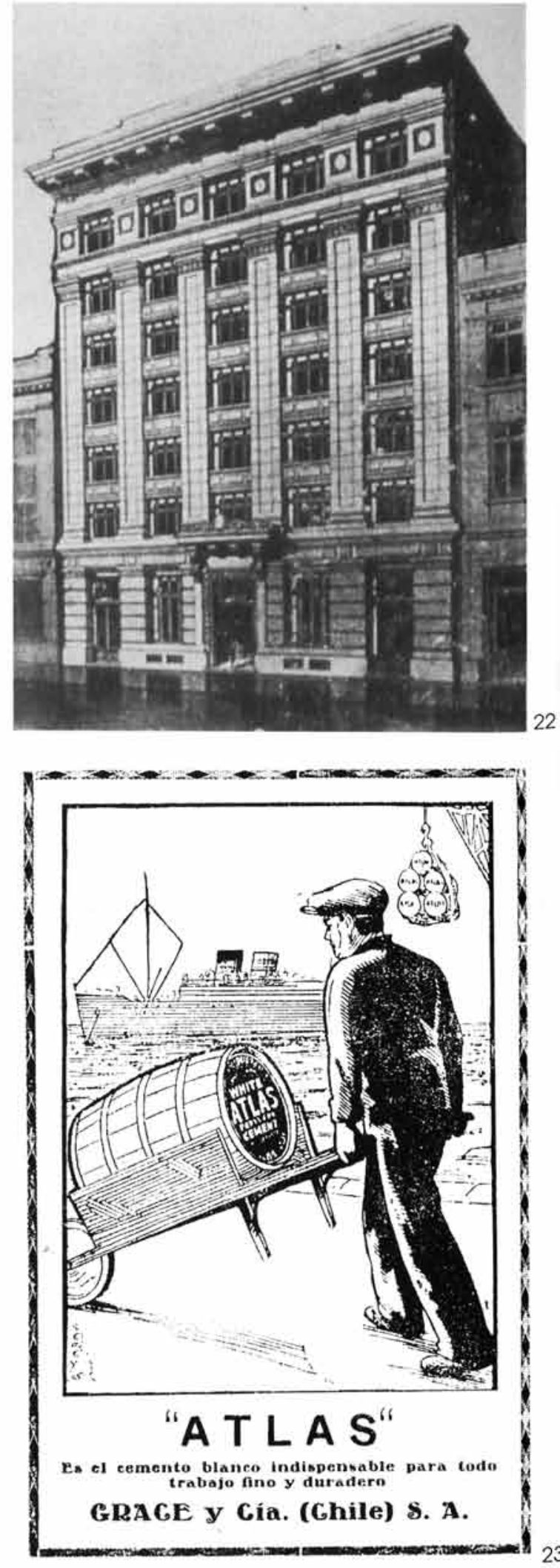

21. Vista del Barrio Cívico y. Plaza Bulnes, Santiago, 1935 aprox. A.A.B.,U.F. U. de Chile.

22. Edif.Banco Nacional de Valparaiso. Arqto. Augusto Geiger. Dibujo en Revista El Arquifecto. N* 4. 1925

23. Publicidad de cemento. 

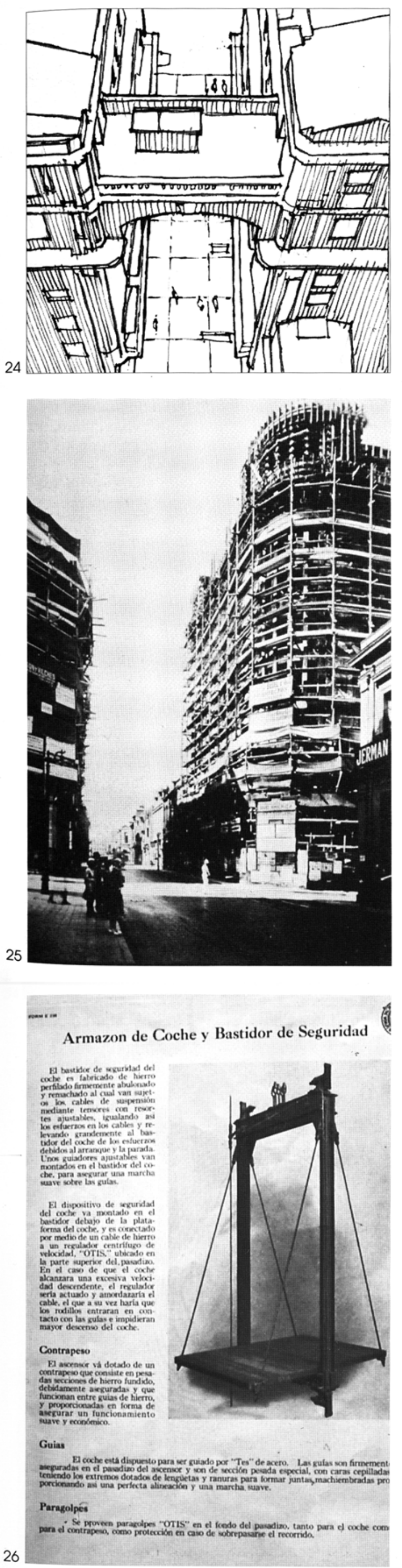

24. Edificios Monjitas 860 . Arqtos. Siegel y Geiger, 1928

25. Construcción de edificios del sector financiero, calles Agustina y Bandera. Foto Merton, en: A. y A.D. № 11.
26. Página de catálogo de ascensores OTIS. Form E 235. quitectura de Ferrocarriles del Estado y de la Armada Nacional. En la plaza Victoria, en 1937 A.Vargas (31) construyó un importante conjunto formado por un teatro, departamentos y comercio en ocho pisos en un terreno de $1.600 \mathrm{~m}^{2}$ Otro ejemplo a destacar es el edificio de la Caja de Previsión de la Marina Mercante, obra del Arquitecto I. Sasso, de ocho pisos de altura en la esquina N.O. de las calles Condell y Ramírez.

\section{Aspectos Tecnológicos.}

A diferencia de lo ocurrido en EE. UU., donde las estructuras de acero cumplieron un rol fundamental (32), en Chile todas estas obras fueron producto del empleo de la tecnología del hormigón armado.

Al conocerse en el país la técnica elemental de uso de este material, fue entusiastamente incorporada a la construcción y pasó a ser considerada la única adecuada para hacer frente a las características sísmicas del territorio.

Un hecho destacado había sido, en 1909 la instalación de la primera fábrica de cemento en Chile (El Melón, La Calera) que permitió el empleo integral de este material, que anteriormente se importaba al país desde EE. UU. y que sólo se usaba en morteros y estucos. Respecto al acero, éste debió seguir importándose ya que el producido en el país era de muy baja resistencia.

El primer intento de instalar en Chile altos hornos es sólo de la primera década del siglo $X X$; los altos hornos de Corral, filial de la firma francesa Schneider y Co., Creusot, que los mantuvo en funcionamiento de 1910 a 1911. Sólo en 1924 volvieron a trabajar con la formación de la "Compañía Electrosiderúrgica de Valdivia" (33).

Los primeros edificios en altura debieron ser construidos empleando los mínimos recursos técnicos. Cabe señalar que el empleo de máquinas betoneras recién se generalizó en 1930 cuando fueron contratadas empresas norteamericanas para pavimentar las calles de Santiagó.

El empleo del hormigón armado como elemento soportante inicialmente fue asimilado en su expresión a materiales ya conocidos (albañilerías de ladrillo o piedra). Naturalmente comenzó a mostrar las posibilidades formales y estructurales propias, al comprobarse una modificación en las dimensiones de los elementos y de los espacios logrados. El mayor interés de gran parte de estas obras es su novedosa estructura compuesta por muros perimetrales y pilares y vigas interiores de hormigón armado que permiten una planta libre. Fueron los arquitectos que habían tenido oportunidad de experimentar con anterioridad con este material, los que proyectaron los edificios del período de introducción de este tipo arquitectónico. Tal fue el caso de los arquitectos formados en el extranjero: Smith Solar (EE. UU.), Siegel y Geiger (Alemania), Cruz Montt, Larraín Bravo y Valdivieso (Francia), quienes poseian experiencia en el empleo de hormigón armado previa a sus primeros proyectos de edificios en altura.

La preocupación por el comportamiento a las solicitaciones sísmicas hacía que los elementos soportantes de hormigón armado estuvieran a menudo sobredimensionados. Esto otorgaba a las obras expresión de fortaleza. El dimensionamiento de las estructuras se hacía en forma intuitiva sin una práctica generalizada de cálculo estructural.

Sólo con posterioridad al terremoto que afectó la región central chilena en 1928, el gobierno contrató a ingenieros franceses y ho- landeses que con sus aportes metodológicos cooperaron en la difusión del empleo del cálculo estructural. Consecuencia de esto fue promulgada una ordenanza que obligaba al uso de pilares y cadenas de hormigón armado en las construcciones de albañilería de ladrillos. Posteriormente fue dictada la Ley № 4563 de 1929 que reglamentó la construcción y la urbanización.

\section{Aspectos formales.}

Cabe hacer notar que todos estos nuevos edificios, además de la singularidad lograda comparativamente por su altura, adquirieron gran presencia respecto a su entorno, sea por su ubicación en esquina o por enfrentar el vacío de una plaza.

En ellos destacaba la apariencia de masa, de cuerpos cerrados, como resultado del predominio de grandes muros perforados. Esta expresión formal corresponde al sistema estructural empleado: muros soportantes.

Al referirnos a la forma-volumen de estos edificios, es necesario destacar que corresponden a cuerpos que ocupaban el total o gran parte del predio en que se emplazaban. Los espacios no construidos corresponden sólo a pequeños patios de ventilación o iluminación. Al estudiar la proporción del plano de sus fachadas se advierte que generalmente la altura era similar o inferior a la longitud del frente. Esta proporción, compositivamente no deseada, se modificaba visualmente recurriendo a seccionar el frente del edificio en varios volúmenes o recurriendo a resaltes de líneas trabajadas con el estuco para acentuar la verticalidad. En las esquinas esto se lograba con mayor facilidad al quebrar las fachadas produciendo ochavos redondeándolas.

Tanto en la composición general de los cuerpos, como en las fachadas, se aplicaban los cánones clásicos de distinguir un basamento o zócalo, en el nivel público cercano a la acera, un desarrollo o cuerpo central y una coronación o remate superior.

Una característica en el quehacer arquitectónico de este período es la coexistencia de tendencias eclécticas historicistas y la voluntad de renovación arquitectónica, expresada con los primeros intentos racionalistas, que fueron inicialmente conocidos a través de publicaciones norteamericanas.

Se reconoce claramente una "lógica" arquitectónica: los proyectistas emplearon un variado repertorio formal según el tipo y carácter de la obra encargada. A modo de ejemplo es posible mencionar que, en un mismo momento, la oficina de los arquitectos Smith y Smith proyectó edificios racionalistas en la Plaza de la Constitución, casas neogóticas en la calle Dieciocho de Santiago y la Sede de la Universidad Santa María de Valparaíso en estilo Tudor. De igual manera el Arqto. Cruz Montt diseñó casi simultáneamente el "rascacielos Ariztía" y el "Club de La Unión". Este último edificio con un fuerte carácter monumental en el que combinó diversos órdenes clásicos para diseñar la sede de un club de la alta burguesía santiaguina.

En los edificios residenciales de la Plaza de Armas, Arteaga utilizó un incipiente lenguaje racionalista al que incorporó ornamentación estilística renacentista y paralelamente proyectó, asociado con S. Larraín, el edificio de oficinas "Oberpaur", cuya novedad formal residía en el dinamismo horizontal producto del juego de franjas de ventanas y antepechos totalmente desprovistos de decoración.

En la obra de Ricardo González aparece con mayor nitidez y persistencia una expresión formal que encontró numerosos seguidores. 

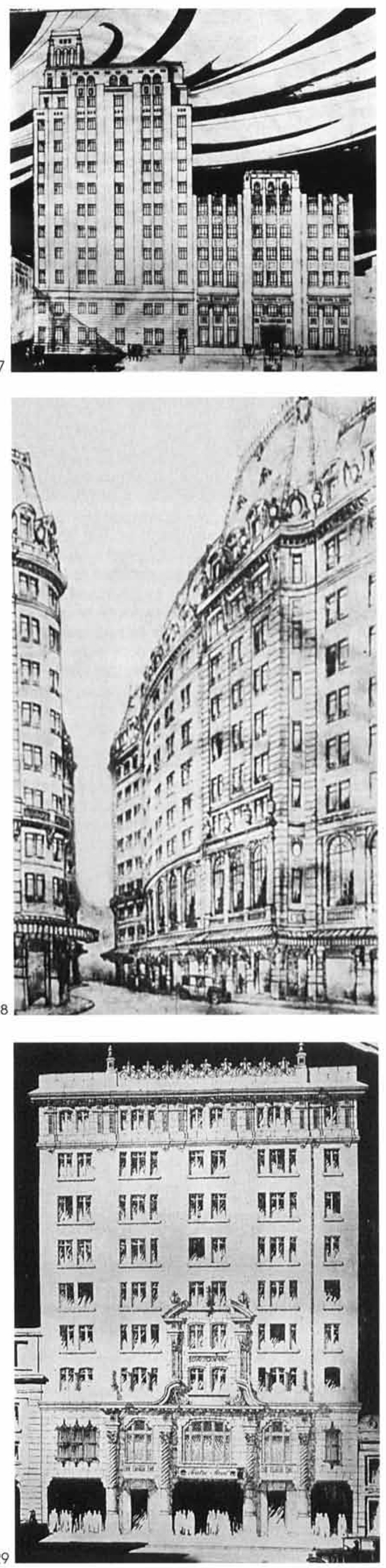
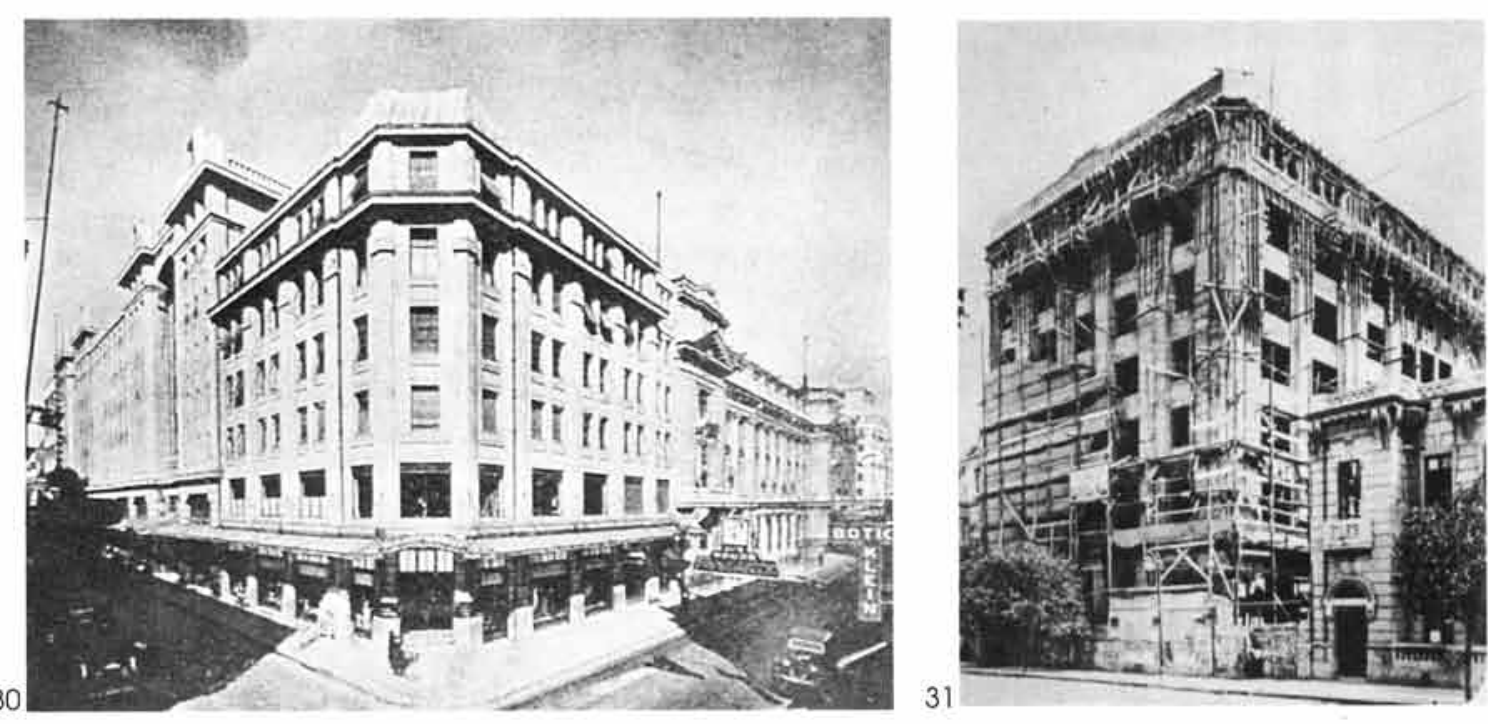

Asimilando algunos de los postulados formales del Art Deco europeo, intentó desarrollar una expresión "nacionalista", empleando grecas aborígenes, flores autóctonas y otros elementos decorativos en zócalos, cornisas, puertas (34) etc. Así también buscó conferir a sus edificios un marcado sentido vertical modificando o suprimiendo los remates superiores. De la técnica del hormigón armado y la necesidad de expresar el refuerzo de las estructuras nació el acartelamiento de los dinteles, que dio como resultado una forma muy característica en las obras de este arquitecto. El edificio de la Caja Nacional de Ahorros de Valparaíso, de nueve niveles, se considera la primera obra en que aplica su personal manera de plantear la arquitectura moderna.

Otro caso destacable de esta expresión es la obra, de seis pisos, en la esquina de las calles 21 de Mayo y Rosas, construido entre 1928 y 1930 según proyecto de los arqtos. R. Larraín y V. Jiménez (35).

\section{Localización, impacto urbano, escala.}

En sus orígenes la edificación alta se localizó en el casco histórico completando o modificando el damero fundacional y configurando, en Santiago, el borde cercano al río Mapocho. En todo caso implicó una modificación significativa del espacio público (creación de nuevas plazas, alteración de la red vial) y, generalmente, una modificación del tejido predial. Esto unido al cambio de estatura de los cuerpos edificados y a la escala de la intervención (cuarto de manzana, media manzana, manzana, varias manzanas) hicieron de estas transformaciones rotundas configuraciones de un nuevo orden urbano arquitectónico y una ruptura con el existente.

\section{Masa edificada y expresión arquitectónica.}

Los cuerpos tendieron a llenar el predio 0 . cuando éstos ocupaban más de un cuarto de manzana, a construir un perimetro edificado (el borde de la calle) con un interior sin edificar o de menor altura (centro de la manzana): edificio tipo pantalla; o constituirse una masa compacta rodeada de calles y pasajes: edificio manzana. Cuerpos de apariencia estable, pesada, opacos, compactos, cerrados, con predominio del lleno sobre el vano.

\section{Destino y significado.}

os nuevos edificios se destinaron principalmente a oficinas y servicios. Suelen contener cines y comercio. Hacia fines del periodo se destinaron a viviendas para grupos sociales de ingresos altos o medio altos.

Casos singulares se constituyeron en hitos de gran valor expresivo y significación social. Aparecen como monumentos y símbolos del poder público del Estado o del poder emprendedor del sector privado, representando la imagen (motivo de orgullo y controversia) de la modernidad y el desarrollo.

Los centros de Santiago y Valparaíso reforzaron su imagen de ciudades capitales al renovar la edificación de sus lugares públicos tradicionales o recién creados, y de sus distritos financieros.

Los edificios de este período se emparentan más con la edificación europea (continua de hasta seis pisos sin ascensor, conformando norteamericanos. Durante el período de introducción de la edificación en altura en Chile. en Estados Unidos de Norteamérica se construyeron los edificios que han permanecido como los más altos del mundo: "Woolworth" (Nueva York 1913, Arqto. C. Gilbert, sesenta pisos y $241 \mathrm{~m}$. de altura); "Empire State" (N.Y. 1931. Arqto. W.Lamb, 380 m.); "Chrysler" (N.Y. 1930. Arato. W.Van Alen, setenta y un piso, 343 m.). En Río de Janeiro se construye en 1928 el Edificio "Guinle", de dieciséis pisos, según proyecto de los arquitectos Gusmao, Dourado y Baldassini, y, en 1929, el Ed. "A Noite" de veintidós pisos, obra de los arqtos. Joseph Gire y Elisiário Da Cunha Bahiana, considerado "primeiro verdadeiro arranha-céu da cidade" (36). En Buenos Aires el edificio Kavanagh (Aratos. Sánchez, Lagos y De la Torre, 1934-35) se levanta en calle Florida esa. San Martín con sus treinta y tres pisos, $110 \mathrm{~m}$. de altura, 12 ascensores y 105 departamentos.

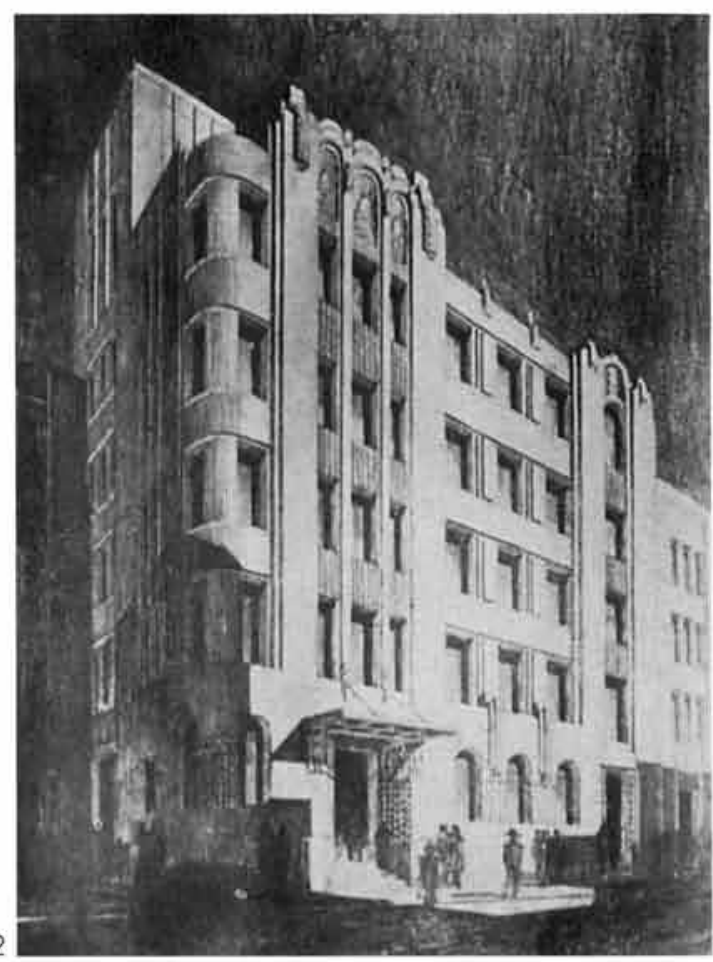
manzanas compactas), que a los rascacielos Julio $1939^{\circ}$

Construcción del Edit. Caja de Empleados Públicos y Periodistas. Arqtos. Monckeberg y Aracena. Foto Merton. 1930. en: A. Y A.D Dibujo del instituto Sanitas, calle Teatinos. Arato. José Alcalde (19) de Chile, 1926). Revista A. y A.D. noviembre 1930. 


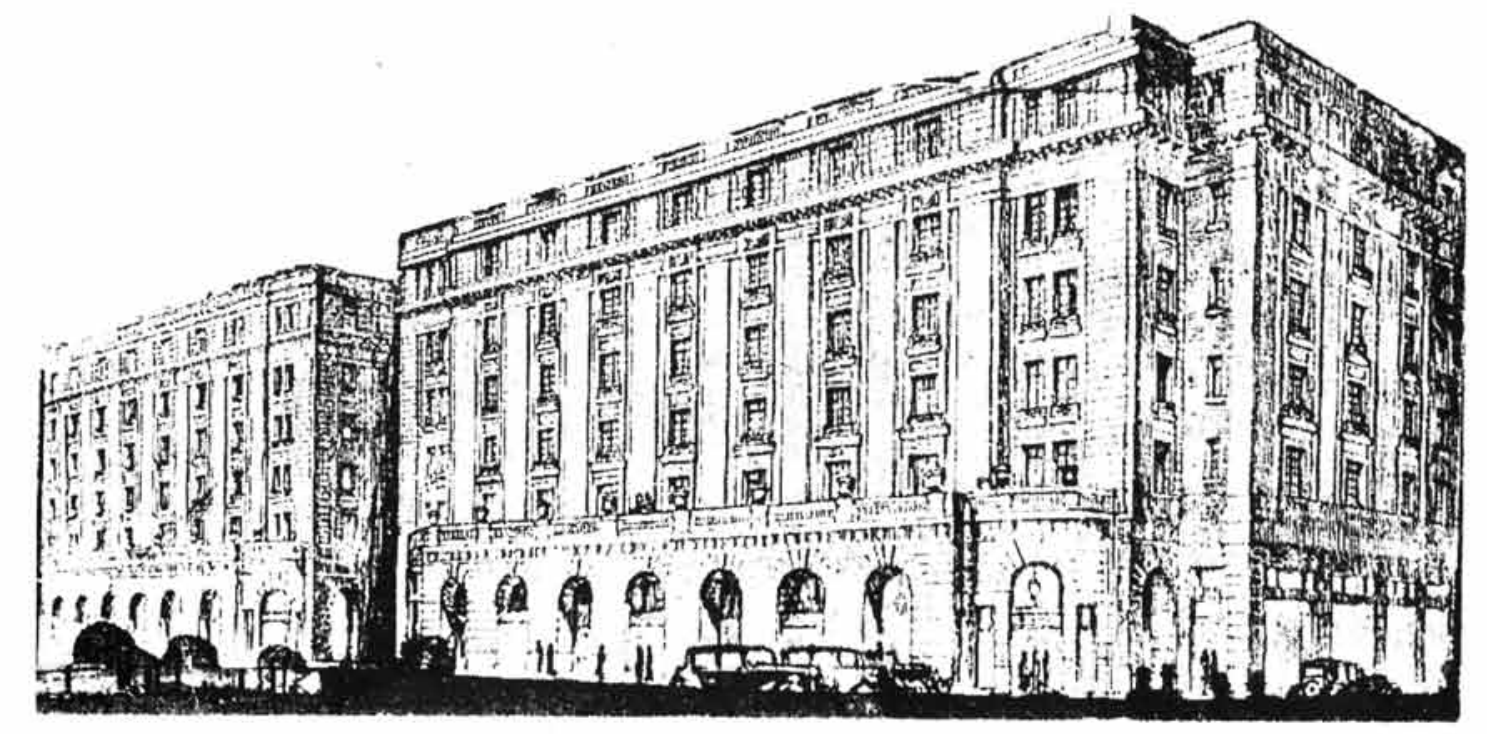

33
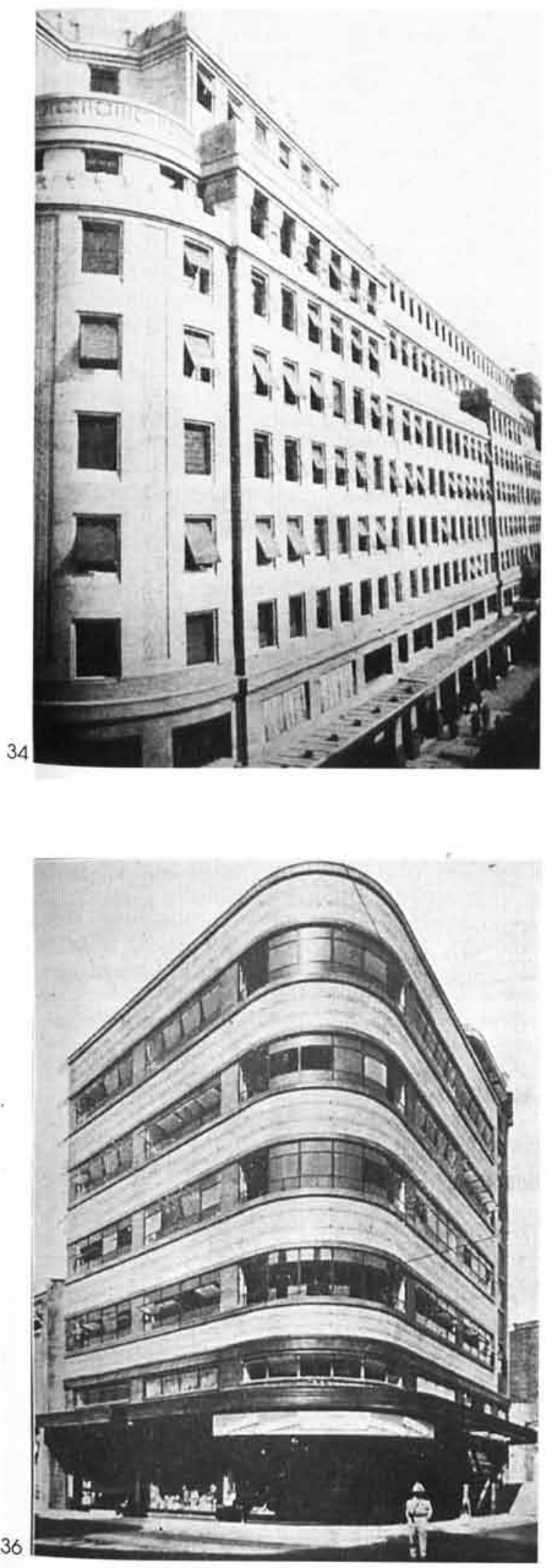

33. Edif. Portal Buines, Plaza de Armas, Santiago. Dibujo en: A. y A.D. 34. Edifiembre de 1931

erificio calle Manios Cousiño. Aratos. Siegel y Siegel. Repartidas en calle: en subterróneo "salón de exibiciones" En 3er. piso galería con local de reunión y exposiciones, libreria y venta de "objetos
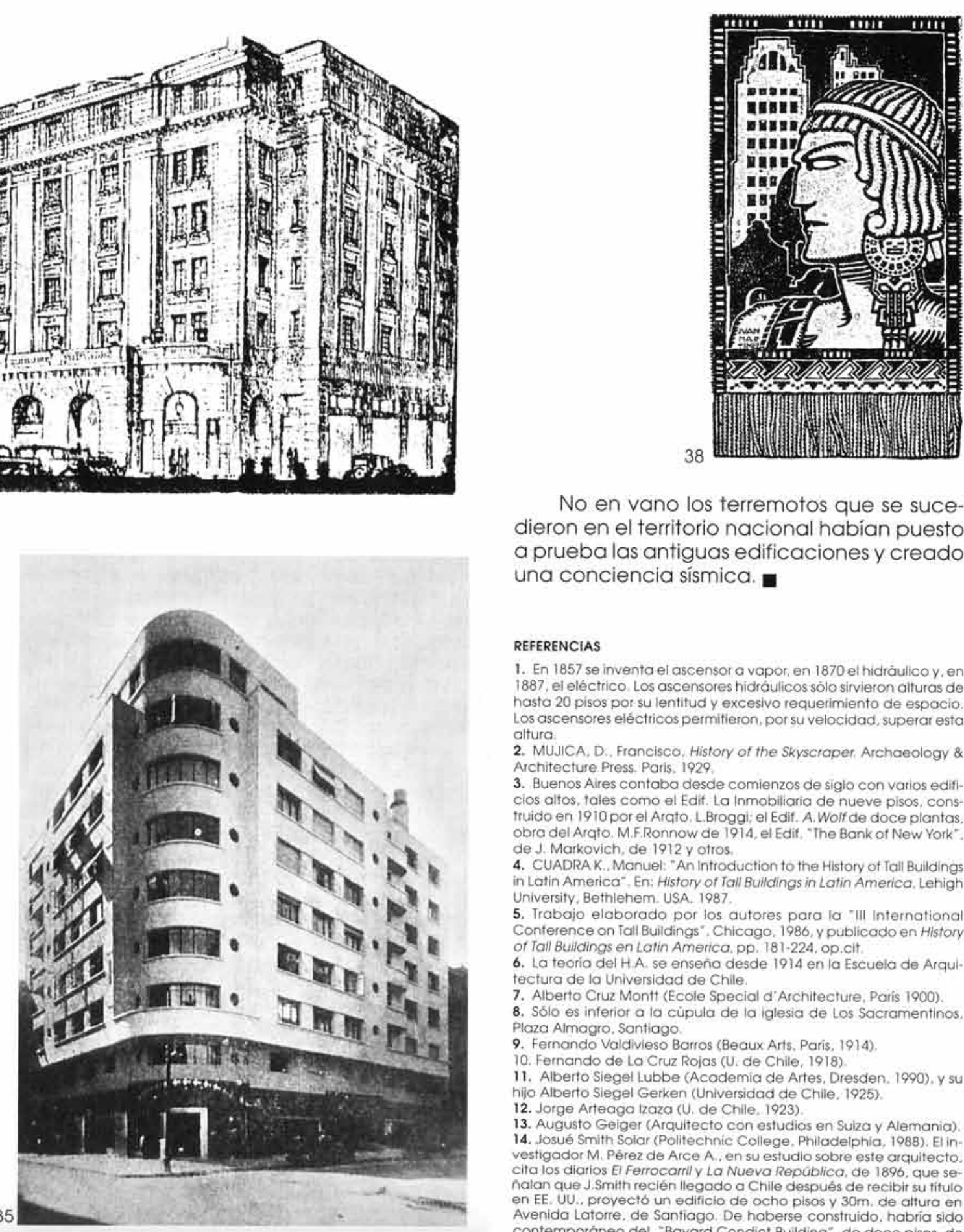

No en vano los terremotos que se suce dieron en el territorio nacional habían puesto a prueba las antiguas edificaciones y creado una conciencia sísmica.

REFERENCIAS

1. En 1857 se inventa el ascensor a vapor, en 1870 el hidráulico y. en 1887, el eléctrico. Los ascensores hidraulicos sólo sirvieron alturas de os ascenisos por su lentifud y excesivo requerimiento de espocio. 2. MUJICA, D. Francisco. History of the Skyscraper. Archaeology \& Architecture Press. Paris, 1929

3. Busos Aires conlaba dosde comienzos de siglo con varios edir Thu dos 1910 coms . Markovich, de 1912 y otros. Jall Bullding 5. Trabaio elaborado por los autores para la "III Internation Conference on Tall Buildings ", Chic 6 . tectura de del H.A. se enseña des.

7. Alberto Cruz Montt (Ecole Special d'Architecture, París 1900). 8. Solo es inferior a la cúpula de la iglesia de Los Sacramentinos. 9. Fermagro, Santiago

11. Alberto de la Craz Rojas (U. de Chile, 1918).

hijo Alberto Siegel Gerken (Universidad de Chile. 1925).

12. Jorge Arteggo raza (l) de Chile. 1923 )

13. Augusto Geiger (Arquitecto con estudios en Suize y Alemania).

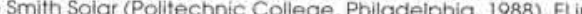
vesigador M. Perez de Arce A., en su estudio sobre este arquitecto.

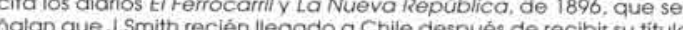
en EE. UU., proyectó un edificio de ocho pisos y $30 \mathrm{~m}$. de altura en Avenida Latorre, de Sanfiago. De haberse construido. habría sido contemporáneo del "Bayard Condict Building", de doce pisos, de

CAUA -IDIE-(C RÍEIITの-

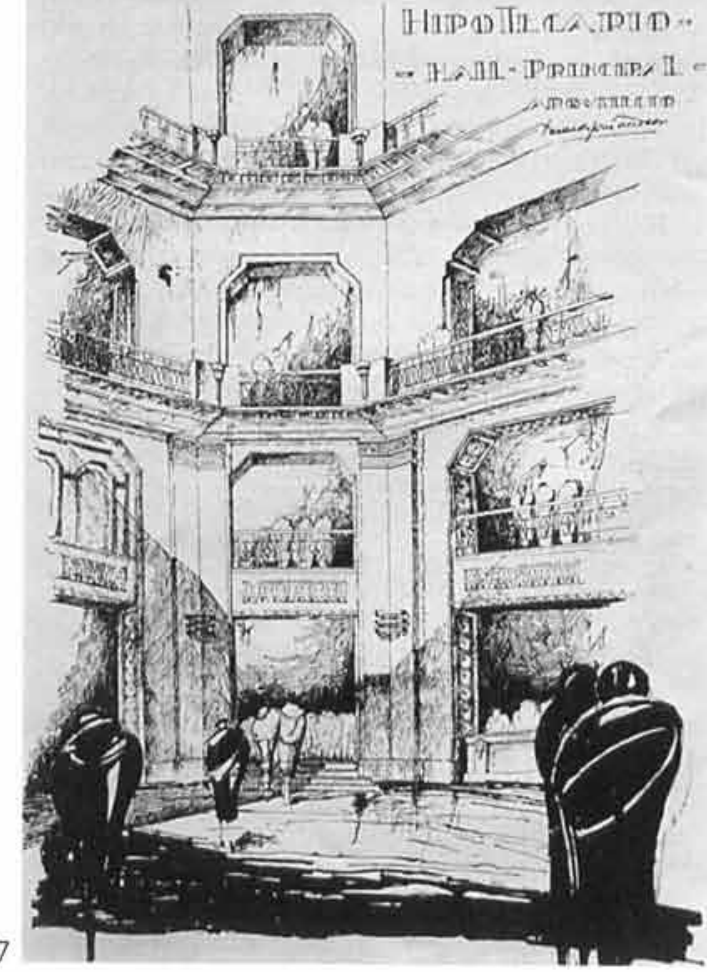

15. Gulllermo Schneider Vergara (U. de Chile, 1918)

16. Luciano Kulczewski Garcia (U. de Chile, 1918). 17. Ricardo Larrain

18. Tomás Armstrong Ariztía (U. Católica. 1916)

19. Italo Sazzo Scampini (U. de Chile, 1917).

20. Carlos Vera Mandujano (U. de Chile, 1924).

21. Roberto Barceló Lira (sin información de estudios).

22. Ricardo González Cortez (U. de Chile, 1913).

23. Anibal Fuentealba Bonniard (U. de Chile, 1925).
24. José T. Edison Smith Miller (U de Chile, 1920)

25. Hernón Rojas Santa Maria (U) Católica, 1923).

26. Sergio Larrain Garcia-Moreno (U. Católica, 1928),

27. Hëctor Mardones Restat (U. de Chile, 1929).

28. Eduardo Costabal Zegers (U. Católica, 1927)

29. Andrés Garafulic Yankovic (U. Católica, 1928).

30. Ambrosio del Rio Aldunate (U. de Chile, 1924)

33. PALMER. Montserrat, 50 anos de Arquitectura Metálica en Chile 1803-19/3, Santiago, Ed. FAU. U. de Chile, 1970.

. do en Rio de Janeiro. se señala la compatibilidad entre los concepclón de las expresiones arquitectónicas

35. Victor liménez Cruz (U) de Chile, 1921 .

36. Guía da Arquitetura Art Decono Rio de Janeiro, Prefeitura Da Cidade do Rio de Janeito, Secretarí Municipal de Urbanismo. sif.

Abreviaturas utilizadas:

A.A.B.U.F., U. de Chile: Archivo Andrés Bello, Unidad de Fotografio

A. Y A.D.. Revsta Anquilectura Y Arte Decorativa.

U. Y A. Revisto Urbanismo y Arquitectura.

de arte " En 6 " piso. estudio de grabación de discos y la emisora de radio R.C.A. Victor Chilena. En $9^{\circ}$ y $10^{\circ}$, un instituto de Educación Fisica, con dos gimnasios En el resto de los pisos, 287 oficinas "con Edificios de Rentas y 204 tolletes: En: U. A, Junio-julio $1939^{\circ}$ Guillermo Kaulen y José Carles para la Caja de Previsión y Estímulo de lormo Kaulen y Jose Canles para la Caja de Prevision y Estimulo 